DOI: 10.12957/demetra.2015.16723

\title{
Condições higiênicossanitárias em quiosques de praia em Vila Velha-ES
}

\section{Hygienic-sanitary conditions of beach kiosks at vila Vila Velha-ES, Brazil}

\author{
Ana Sarah Brito Portugal ${ }^{1}$ \\ Juliana Manhães Iulianellor \\ Maria Cristina Almeida Batista Goltara' \\ Láiza Sulti Medeiros' \\ Jackline Freitas Brilhante de São José ${ }^{\prime}$ \\ Erika Madeira Moreira da Silva' \\ ' Universidade Federal do Espírito Santo, \\ Departamento de Educação Integrada em Saúde, \\ Curso de Nutrição. Vitória-ES, Brasil. \\ Correspondência / Correspondence \\ Jackline Freitas Brilhante de São José, \\ Departamento de Educação Integrada em Saúde, \\ Universidade Federal do Espírito Santo, Av. \\ Marechal Campos, 1468, Maruípe, Vitória-ES, \\ Brasil. CEP 29.040-090 \\ Email: jackline.jose@ufes.br
}

\section{Resumo}

Objetivou-se avaliar as condições higiênicossanitárias em dez quiosques localizados em Vila Velha-ES. Os dados foram coletados por meio de observação direta com o preenchimento de lista de verificação baseada na Resolução RDC n²16/2004. Essa lista foi elaborada considerando-se 11 blocos a serem avaliados onde, ao final, os estabelecimentos foram classificados no Grupo 3 , de acordo com o percentual de atendimento aos itens constantes na lista de verificação (0 a 50\%). Destaca-se a inexistência de fechamento automático nas portas e de tela milimétrica nas janelas. O espaço físico dos quiosques é padronizado, porém não possibilita fluxo ordenado e sem cruzamento. Os equipamentos, móveis e utensílios eram mantidos em condições higiênicossanitárias inapropriadas em todos os quiosques. Nenhum estabelecimento possuía local próprio para guarda de produtos saneantes, sendo estes mantidos próximos aos alimentos. Quanto ao controle integrado de pragas e vetores foi observado atendimento acima da média $(66,66 \%)$ dos itens avaliados. Em relação às práticas de manipulação, observou-se que nenhum estabelecimento possuía sabonete antisséptico nem instruções para lavagem correta das mãos. Foram observadas inadequações em todos os itens referentes a matéria-prima, armazenamento, bem como a documentação e responsabilidade. As condições higiênicossanitárias dos quiosques são insatisfatórias, sendo necessárias mudanças comportamentais e estruturais.

Palavras-chaves: Qualidade. Boas Práticas de Manipulação. Segurança dos Alimentos. Serviços de Alimentação. Qualidade dos Alimentos. 


\section{Abstract}

The aim of this study was to evaluate hygienic sanitary conditions in ten kiosks located on the beach of Vila Velha-ES. Data were collected through direct observation by a checklist based on RDC Resolution no. 216/2004. This list was compiled considering 11 blocks to be evaluated where, at the end, the establishments were classified in Group 3, according to the percentage of attendance to the items listed in the checklist $(0-50 \%)$. The lack of automatic closing doors and millimeter screen at the windows were verified. The physical space of the kiosks is standardized, but does not allow for orderly flow without cross. Equipment, furniture and fixtures were kept in inappropriate hygienic sanitary conditions at all kiosks. There was no appropriate place to keep the sanitizing products, which are kept close to food. According to the integrated control of pests and vectors, $66.66 \%$ of evaluated items were in accordance with the resolution. Regarding handling practices, it was observed that no establishment had antiseptic soap or instructions for proper hand washing. Inadequacies were observed in all items related to raw material, storage, as well as documentation and responsibility. The hygienic sanitary conditions of the kiosks are unsatisfactory, which need behavioral and structural changes.

Key words: Quality. Good Practices of Handling. Food Safety. Food service. Food Quality.

\section{Introdução}

O setor de serviços de alimentação tem sido ampliado, pois a realização de refeições fora do lar tornou-se um hábito entre a população. ${ }^{1}$ Existem alternativas que consideram as adaptações às condições urbanas e geram novas modalidades no modo de comer, o que certamente contribui para mudanças no consumo alimentar, uma dessas alternativas são os quiosques. ${ }^{2}$

O quiosque é uma construção aberta por todos os lados, geralmente com sua planta redonda ou quadrada. Em sua estrutura encontramos a cúpula (que caracteriza seu teto), janelas, balcão e a base, o qual pode funcionar como mini restaurantes em beira de praia e tem finalidade de comercializar alimentos e bebidas para aqueles que frequentam as praias, e necessitam destes serviços. ${ }^{3}$

A crescente procura por esses serviços e a grande concorrência, contribuem para que a qualidade com relação aos aspectos intrínsecos ao alimento (qualidade nutricional e sensorial), segurança (qualidade higiênicossanitária), atendimento (relação cliente-fornecedor) tornem-se 
fundamental. Isso devido ao fato do consumo de refeições fora do domicílio ser um hábito que expõe os consumidores ao risco de contraírem doenças alimentares. ${ }^{4}$

Nos últimos anos, o controle higiênico sanitário de alimentos vem sofrendo profundas mudanças conceituais e técnicas, devido aos novos conhecimentos em relação ao controle dos microorganismos causadores de Doenças de Origem Alimentar (DOA's), motivadas, principalmente pelo aparecimento de cepas microbianas mais adaptadas aos antigos e convencionais mecanismos de prevenção. ${ }^{4}$ As DOA’s são umas das principais consequências da falta de controle higiênicossanitários no setor de serviços de alimentação, onde são encontrados perigos, que podem ser biológicos, físicos e químicos. ${ }^{5}$

Deste modo, são imprescindíveis ações de controle nos estabelecimentos que preparam/ manipulam alimentos para minimizar os riscos de contaminação. Para isso, instrumentos legais importantes como as Portarias nº 1428/1993 e nº 326/1997 do Ministério da Saúde e as Resoluções da Agência Nacional de Vigilância Sanitária - RDC no 275/2002 e 216/2004 foram aprovadas com o intuito de contribuir para qualidade na produção e na prestação de serviços na área de alimentação ao orientar sobre as boas práticas de manipulação de alimentos. ${ }^{6-9}$ A RDC n ${ }^{\circ}$ 216, de 15 de setembro de 2004, traz informações sobre as Boas Práticas para Serviços de Alimentação de forma a estabelecer os procedimentos ideais que visam contribuir nas condições higiênicossanitárias dos alimentos manipulados. ${ }^{9}$

O controle das condições higiênicossanitárias nos locais em que os alimentos são manipulados constitui uma tarefa complexa, uma vez que contaminações de diferentes fontes podem ser introduzidas nas diversas etapas da higienização e do preparo do alimento ${ }^{5}$. São várias as formas de contaminação dos alimentos, por isso, devem-se monitorar todas as etapas do processo, como conservação, manipulação, transporte, armazenamento, preparo e distribuição. Uma ferramenta comumente utilizada para verificação das etapas descritas é a lista de verificação, que possibilita quantificar o grau de adequação de determinado estabelecimento de acordo com a legislação. ${ }^{4}$

O presente trabalho teve como objetivo avaliar as condições higiênicossanitária em dez quiosques localizados na orla de uma praia no município de Vila Velha-ES, e classificá-los de acordo com o cumprimento dos itens estabelecidos pela legislação vigente.

\section{Material e métodos}

Trata-se de uma pesquisa de campo, descritiva de abordagem quantitativa, que ocorreu durante o mês de janeiro de 2014 em dez quiosques, o que representa 27,77\% do total de 36 quiosques existentes, localizados na orla do município de Vila Velha-ES. A amostragem foi feita por conveniência e de acordo com a concordância do dono/responsável do estabelecimento em participar da pesquisa. 
Inicialmente, os responsáveis pelos estabelecimentos foram contatados por meio de carta convite para apresentação dos objetivos da pesquisa e em seguida foi solicitada a permissão para visita e avaliação dos quiosques. Todos os responsáveis pelos estabelecimentos participantes assinaram um termo de autorização para permitir a realização da pesquisa.

A coleta dos dados ocorreu por meio de observação direta durante as visitas realizadas por pesquisador treinado. Para a avaliação, foi utilizada uma lista de verificação baseada na Resolução RDC n²16/2004, dividida em três partes: identificação da empresa, avaliação e classificação do estabelecimento. ${ }^{9}$ A lista de verificação apresentava onze blocos de perguntas avaliados em cada restaurante, totalizando 116 itens, conforme a seguir: 'edificações, instalações, móveis e utensílios' (39 itens); 'controle integrado de vetores e pragas' (5 itens); 'abastecimento de água' (6 itens); 'manejo dos resíduos' (4 itens); 'manipuladores' (11 itens); 'matérias - primas, ingredientes e embalagens' (7 itens); 'preparação do alimento' (21 itens); 'armazenamento e transporte do alimento preparado' (3 itens); 'exposição ao consumo do alimento preparado' (7 itens); 'documentação e registro’ (9 itens) e; 'responsabilidade' (3 itens). Cada item possuía três possibilidades de resposta: 'Conforme', 'Não Conforme' e 'Não se aplica' (NA). ${ }^{8}$

A partir do preenchimento da lista de verificação os estabelecimentos foram classificados em três grupos, de acordo com os critérios de pontuação estabelecido no item D da RDC n²75/2002, quanto à adequação em relação aos itens observados, sendo: GRUPO 1 - 76 a 100\% de atendimento dos itens; GRUPO 2 - 51 a 75\% de atendimento dos itens; GRUPO 3 - 0 a $50 \%$ de atendimento dos itens. ${ }^{8}$ Adotou-se essa mesma classificação para cada um dos onze blocos da lista de verificação. Os dados obtidos na avaliação das condições higiênicossanitárias por meio da lista de verificação foram armazenados em planilhas do Microsoft Excel $^{\circledR}$ e tabuladas adotando os valores de percentual de adequação.

\section{Resultados}

Em relação ao atendimento aos itens propostos na lista de verificação, o percentual de adequação dos quiosques variou de 20,5\% a 23,3\%, sendo que todos os quiosques visitados foram classificados no Grupo 3. Na Figura 1, são apresentados os percentuais médios de adequação e inadequação dos itens avaliados, por blocos, na lista de verificação baseada na RDC n²16/2004. ${ }^{\circ}$ 


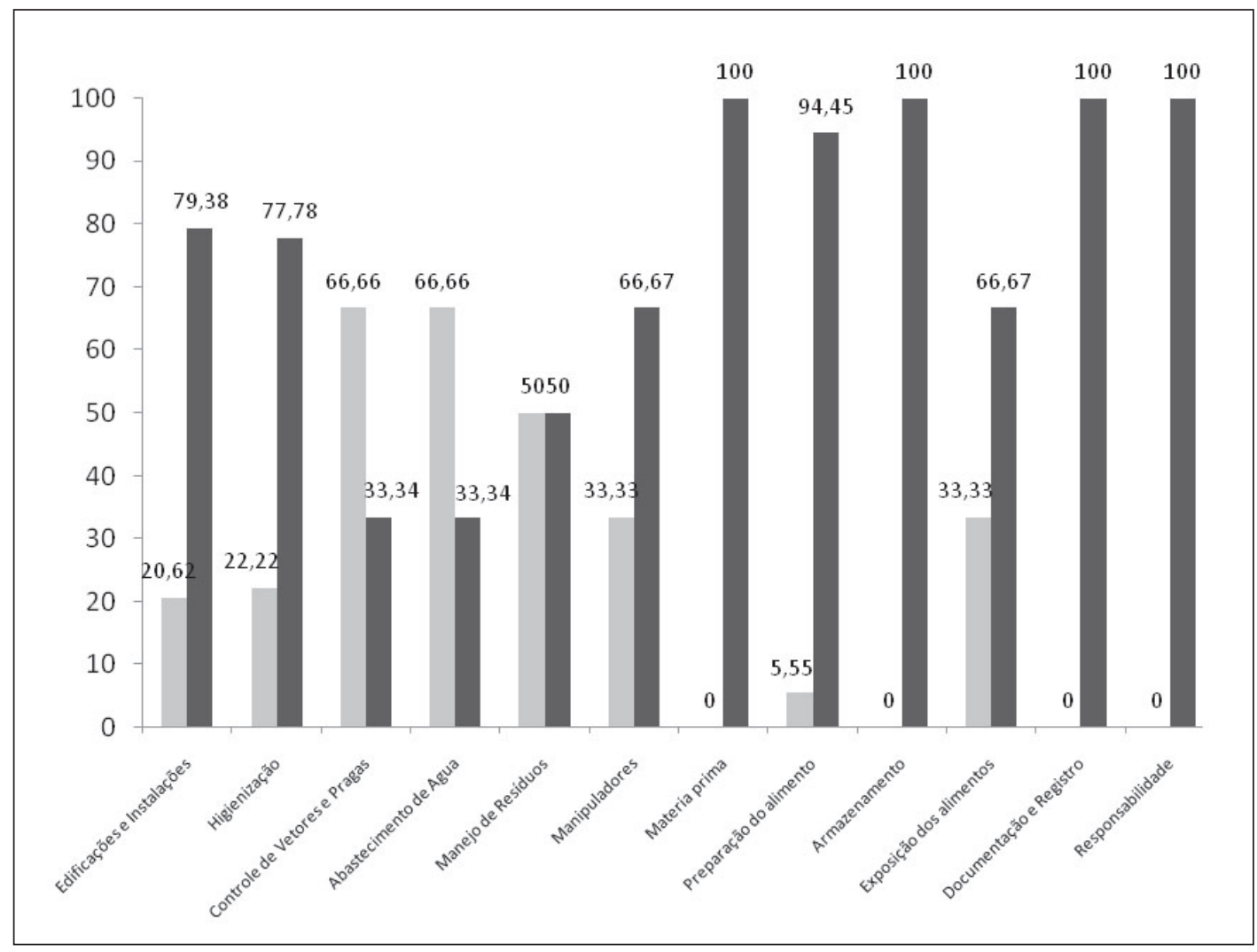

Figura 1. Percentuais médios de adequação ( $\square$ ) e inadequação ( $\square$ ) aos itens relacionados às boas práticas de manipulação, por bloco avaliado, em quiosques localizados na orla de Vila Velha - ES.

No bloco edificações e instalações, o percentual de adequação aos itens variou de 13,33 a 26,66 \% . Devido ao espaço reduzido, determinadas estruturas comuns em áreas de produção de alimentos não existiam nesses estabelecimentos, como por exemplo, a inexistência de fechamento automático nas portas.

Em relação à higienização das instalações, $100 \%$ dos quiosques não mantinham equipamentos, móveis e utensílios em condições higiênicossanitárias apropriadas, e não armazenavam produtos saneantes em local adequado. 
No bloco Controle de Vetores e Pragas observou-se que 66,66\% de adequação dos itens avaliados, demonstrando que a maioria dos estabelecimentos têm preocupação em impedir a ocorrência e proliferação de pragas urbanas.

Do total de itens avaliados no bloco de Abastecimento de Água, em todos os quiosques, houve 33,33\% de adequação. Foi observado que a água utilizada nesses estabelecimentos é proveniente de poços.

Para o bloco de Manejo de Resíduos, todos estabelecimentos analisados o fluxo de lixo não era diferenciado da matéria-prima, o que pode facilitar contaminação cruzada. Isso contribui para atrair mau cheiro, pragas urbanas e propiciar a contaminação do produto, considerando-se a aproximação excessiva desses coletores de lixo do ambiente de manipulação e distribuição dos alimentos.

Quanto ao bloco manipuladores, foi observado 33,33\% de adequação aos itens em todos os estabelecimentos. A baixa adequação significa risco para os consumidores, visto que o manipulador é o principal promotor de uma possível contaminação.

Neste bloco Matérias-primas e ingredientes, todos os quiosques obtiveram 100\% de inadequação. Destacam-se falhas no recebimento e no armazenamento, onde as matérias-primas recebidas não são criteriosamente avaliadas e acondicionadas em locais apropriadas que garantam a condição higiênicossantária dos alimentos. A recepção dos alimentos não era realizada em local limpo e protegido e a matéria-prima não era armazenada de forma adequada, sendo este setor desorganizado e sujo.

No bloco Preparação do Alimento, todos os quiosques obtiveram 5,55\% de adequação. Foi observado que o descongelamento de alimentos, em 100\% dos quiosques, era realizado em temperatura ambiente, o que favorece a multiplicação microbiana. Ainda foi observado que, durante as preparações não são adotadas medidas de prevenção contra contaminação e não era evitado o contato de alimentos crus com alimentos preparados, o que possibilita o risco de contaminação cruzada entre esses alimentos. Os alimentos crus ou prontos e os gêneros que não eram utilizados na totalidade eram armazenados no mesmo local, sem identificação, prazo de validade e data da manipulação. Outra inadequação detectada foi a falta de controle da temperatura do óleo utilizado na fritura de alimentos e também na falha na observação das características físico-químicas e sensoriais que indicam a necessidade de troca. Nesse caso, é possível que o óleo utilizado apresente condições inapropriadas para o consumo.

Os principais problemas encontrados no bloco Exposição ao consumo do alimento preparado foram, a inadequação da área de exposição do alimento preparado, equipamentos sob más condições e com falhas quanto à manutenção da temperatura adequada e os utensílios utilizados na consumação do alimento, de materiais de difícil higienização e armazenados inadequadamente. 
Outro grave problema detectado foi que a área de recebimento de dinheiro, cartões e outros meios utilizados para o pagamento, é a mesma na qual os alimentos são preparados. Além disso, os funcionários responsáveis por essa atividade também manipulam alimentos.

No bloco Documentação e Registro, o percentual de inadequação foi de $100 \%$ nos dez quiosques, sendo todos classificados no Grupo 3. A Resolução preconiza que os serviços de alimentação devam estabelecer as Boas Práticas por meio de documentos, para garantir as condições higiênicas sanitárias do alimento preparado.

No presente estudo foi observado que $100 \%$ dos quiosques estavam inadequados quanto aos itens do bloco Responsabilidade.

\section{Discussão}

Este estudo mostrou as diversas falhas presentes nos quiosques de praia que comercializam alimentos e bebidas. São falhas relacionadas tanto à estrutura física-funcional do local até a distribuição dos alimentos. Tais intercorrências contribuem para redução da qualidade higiênicossanitárias dos alimentos comercializados nestes estabelecimentos.

Estes resultados contrastam quando se compara com os dados obtidos por Nascimento et al. ${ }^{10}$, em que observou-se que 50,78\% dos quiosques avaliados, localizados na orla de Vitória-ES, estavam em condições higiênicossanitárias adequadas.

A adequação da edificação e instalações constitui uma condição que facilita a implementação das boas práticas nas etapas de manipulação dos alimentos. Devem ser construídas de forma a possibilitarem um fluxo ordenado e sem cruzamentos em todas as etapas da preparação de alimentos e a facilitar as operações de manutenção e higienização. ${ }^{8,9}$ Sabe-se que o espaço físico dos quiosques é padronizado, porém o dimensionamento da edificação e das instalações não é compatível com todas as operações.

No trabalho realizado por Assis et al., ${ }^{4}$ foi encontrado inexistência de fechamento automático nas portas em todos os quiosques e de tela milimétrica nas janelas em 85,71\% $(n=24)$ dos mesmos. Nascimento et al. ${ }^{10}$ fizeram um levantamento das condições sanitárias de quiosques na cidade de Vitória-ES e observaram que os equipamentos e utensílios eram inadequados e armazenados de maneira incorreta. Já Almeida e Hostins ao avaliarem a estrutura física dos quiosques identificaram que 95,6\% se encontravam em bom estado de conservação. ${ }^{11}$

De acordo com Fonseca et al., ${ }^{12}$ um dos pontos fundamentais para implementação das boas práticas e qualidade dos alimentos preparados é a adequação de edificações, instalações, equipamentos, móveis e utensílios. Quando estas são projetadas adequadamente, facilitam a 
ordenação do fluxo de produção e evitam cruzamentos em todas as etapas da preparação de alimentos, e contribuem para as operações de manutenção, limpeza e desinfecção.

Quanto à higienização das instalações, os alimentos podem ser contaminados pelo contato com utensílios, superfícies e equipamentos insuficientemente limpos. Assis et al. ${ }^{4}$ constatou que $71,43 \%(n=20)$ dos quiosques não apresentavam equipamentos de fácil acesso e higienização, e que $71 \%$ ( $n=21$ ) dos quiosques não possuíam local próprio para guardar os produtos de limpeza. De acordo com a legislação vigente, as superfícies dos utensílios devem ser lisas, impermeáveis, laváveis e isentas de rugosidades, frestas e outras imperfeições que possam comprometer a higienização dos mesmos, não favorecendo assim a contaminação dos alimentos. ${ }^{9}$ Porém, todos os quiosques visitados apresentaram utensílios irregulares quanto às normas preconizadas pela RDC $n^{\circ} 216 / 2004 .{ }^{9} \mathrm{O}$ resultado encontrado é preocupante, pois a presença de rugosidades, frestas e outras imperfeições associadas a uma higienização irregular ou inadequada podem favorecer a proliferação microbiana e consequente formação de biofilme microbiano.

Quanto ao controle de pragas, em estudo realizado por Assis et al., ${ }^{4}$ foi encontrado que a metade $(n=14)$ dos quiosques estavam em adequação com a legislação apresentando certificado visível e com a data de validade vigente. O Controle Integrado de Pragas (CIP) é indispensável nos serviços de alimentação, pois este ambiente comumente oferece os três elementos facilitadores para o desenvolvimento das pragas urbanas: alimento, abrigo e água. ${ }^{13}$ É necessário impedir a atração, o abrigo, o acesso e ou proliferação de vetores e pragas urbanas em restaurantes, isso é possível através da aplicação de um conjunto de medidas eficazes e contínuas de controle de pragas. ${ }^{14}$

Apesar de não ter sido realizada a análise microbiológica da água utilizada, outros estudos como o de Colvara et al. ${ }^{15}$ no qual avaliaram a qualidade de águas provenientes de poços artesianos, há indícios de inadequação quanto aos padrões microbiológicos estabelecimentos. A qualidade da água utilizada no preparo dos alimentos e em procedimentos de higienização é fundamental para contribuir na qualidade final das refeições preparadas. Desse modo, estes quiosques ao utilizar água de poço, a qual não recebe tratamento para garantir potabilidade, põe em risco a qualidade dos alimentos servidos. O controle de qualidade da água para qualquer uso na produção de alimentos é necessário para evitar possíveis riscos à saúde dos consumidores dos produtos comercializados. Portanto, a água deve ser potável, para isso é necessário que o reservatório esteja íntegro, limpo e tapado para manter a qualidade..$^{13}$

O manejo de resíduos também foi avaliado nos quiosques e nenhum dos estabelecimentos atendia ao preconizado na Resolução $n^{\circ}$ 216/2004. ${ }^{9}$ Este descumprimento da resolução pode acarretar em um prejuízo para o estabelecimento, pois pode atrair diversas pragas e vetores urbanos. Além disso, vale ressaltar que em $100 \%$ dos estabelecimentos analisados o fluxo de lixo não era diferenciado da matéria-prima, o que pode facilitar contaminação cruzada. Isso contribui para atrair mau cheiro, 
pragas urbanas e propiciar a contaminação do produto, considerando-se a aproximação excessiva desses coletores de lixo do ambiente de manipulação e distribuição dos alimentos.

Resultados semelhantes foram observados por Almeida e Hostins ao avaliarem quiosques na Praia Central de Balneário Camboriú, onde verificaram que quanto ao acondicionamento do lixo, 8,8\% dos estabelecimentos avaliados não cumpriam as determinações para padronização e posicionamento das lixeiras, 21,9\% não higienizavam as lixeiras adequadamente e 12,3\% deles não acondicionarem o lixo conforme estabelecem as normativas. ${ }^{11}$

Quanto ao bloco manipuladores, foi registrada baixa adequação, o que significa risco para os consumidores, visto que o manipulador é o principal promotor de uma possível contaminação. Destaca-se nesse bloco que nenhum estabelecimento possuía sabonete antisséptico para a higienização das mãos e cartaz de orientação da lavagem correta das mãos. Este fato evidencia a ausência de orientação sobre a correta lavagem e antissepsia das mãos, como preconiza a legislação vigente. Assis et al. também observaram as mesmas inadequações em todos os quiosques avaliados. ${ }^{4}$

Observou-se ainda que em nenhum dos estabelecimentos os funcionários utilizavam uniformes compatíveis às atividades, apresentando somente blusa com identificação do estabelecimento como uniforme. Os manipuladores não mantinham os cabelos presos com toucas ou redes. No estudo realizado por Nascimento et al., 44,5\% dos manipuladores usavam avental, 73,1\% utilizavam sapato fechado, apenas 22,7\% estavam com proteção adequada nos cabelos, e 51,3\% estavam com unhas curtas, mãos limpas, sem esmalte e adornos e ausência de afecções cutâneas. ${ }^{10} \mathrm{~A}$ Resolução RDC $n^{\circ}$ 216/2004 relata que os manipuladores devem ter asseio pessoal, apresentando uniformes compatíveis com as atividades, receber treinamento de capacitação sobre higiene pessoal e saber se comportar durante o desempenho das atividades, para que não comprometam a qualidade higiênicossanitária dos alimentos. ${ }^{9}$

Com relação ao treinamento, nenhum dos quiosques avaliados realizava os treinamentos e capacitação dos manipuladores. Situação semelhante foi observada por Gonçalves et al., ${ }^{16}$ onde verificaram que 91,1\% dos manipuladores de quiosques da praia do Itararé não recebiam treinamento relacionado à higiene pessoal e manipulação e 73,3\% não utilizavam uniformes adequados para a atividade. No estudo de Almeida, os manipuladores dos quiosques participaram de treinamentos em boas práticas de manipulação de alimentos, o que indicou a preocupação destes no preparo dos alimentos de forma segura. ${ }^{17}$

Quanto ao recebimento e armazenamento de matérias-primas, é indicado pela legislação vigente que os locais sejam limpos e protegidos para garantir a proteção contra contaminantes e que a matéria-prima seja armazenada sobre paletes, prateleiras feitas de material liso e resistente, com espaçamentos que garantam a adequada ventilação e limpeza quando necessário. ${ }^{9}$ Vale 
ressaltar que no caso dos quiosques, como o espaço é limitado, cabe aos responsáveis pelo local buscar estratégias que garantam a organização e o adequado acondicionamento dos alimentos. Gonçalves et al. ${ }^{16}$ observaram que 73,4\% dos quiosques da praia do Itararé, em São Vicente-SP, não mantinham a temperatura dos estoques controlada e 44,5\% encontravam-se em condições higiênicossanitárias inadequadas.

O percentual de inadequação para a documentação exigida pela legislação foi igual a $100 \%$. A Resolução preconiza que os serviços de alimentação devam estabelecer as Boas Práticas por meio de documentos, para garantir as condições higiênicas sanitárias do alimento preparado. Souza et al. verificaram em estudo que após a implementação do Manual de Boas Práticas em uma unidade de alimentação e nutrição, mudanças significativas ocorreram, e foram ainda maiores após a capacitação dos funcionários, que passaram a se dedicar mais ao cuidado com a higiene e manipulação dos alimentos. ${ }^{18}$ A aplicação dos Procedimentos Operacionais Padronizados contribui para a garantia das condições higiênicossanitárias necessárias ao preparo de alimentos, complementando as Boas Práticas. ${ }^{19}$

Nenhum dos quiosques atendeu aos itens do bloco Responsabilidade. De acordo com a RDC n²16/2004, esses funcionários devem ser submetidos a cursos de capacitação em que sejam abordados no mínimo os seguintes temas: contaminantes alimentares, doenças transmitidas por alimentos, manipulação higiênica dos alimentos e boas práticas. ${ }^{9}$

\section{Conclusão}

As condições higiênicossanitárias dos quiosques são bastante preocupantes, já que itens básicos para a garantia da qualidade do alimento não são seguidos. Podem-se classificar como precárias as condições observadas na grande maioria dos estabelecimentos inspecionados.

As boas práticas de manipulação segura de alimentos não são seguidas integralmente pelos manipuladores de alimentos dos quiosques. Poucos itens atenderam os critérios exigidos pela legislação, o que pode acarretar em alto risco de contaminação alimentar aos frequentadores. Os problemas encontrados são, muitas vezes, de natureza estrutural, podendo ser combatidos com investimentos maciços no setor.

Diante destes resultados verifica-se a importância dos órgãos competentes em realizarem fiscalização frequente com o objetivo de orientar e conscientizar os proprietários e manipuladores de alimentos sobre a importância e benefícios das boas práticas de manipulação segura de alimentos em seus estabelecimentos. 


\section{Referências}

1. Associação Brasileira de Refeições Coletivas. Mercado Real. São Paulo: ABERC; 2015. [acesso em 20 fev. 2014]. Disponível em: http://www.aberc.com.br/mercadoreal.asp?IDMenu=21

2. Garcia RWD. Reflexos da globalização na cultura alimentar: considerações sobre as mudanças na alimentação urbana. Rev. Nutr. 2003; 16(4):483-92.

3. Silva CAN. A poluição visual causada pelos quiosques na faixa de areia da praia da enseada - Guarujá. Rev. Don Domênico [Internet]. 2011. 4 edição. Disponível em: http://faculdadedondomenico.edu. br/novo/revista_don/artigo7_ed4.pdf

4. Assis FS, Vieira CCU, Iuliano BA, Rocha EG, Silva FC, Câmara FM, et al. Avaliação das condições higiênico-sanitárias dos quiosques instalados na companhia de entrepostos e armazéns gerais do estado de São Paulo (CEAGESP). Seg. Alim. Nutr. 2011; 18(2):33-52.

5. São José JFB, Coelho AIM, Ferreira KR. Avaliação das boas práticas em unidade de alimentação e nutrição no município de Contagem-MG. Alim. Nutr. 2011; 22(3):479-487.

6. Brasil. Ministério da Saúde. Portaria no 1.428, de 26 de novembro de 1993. Aprova Regulamento Técnico para Inspeção Sanitária de Alimentos, Diretrizes para o Estabelecimento Boas Práticas de Produção e de Prestação de Serviço na Área de Alimentos e o Regulamento Técnico para o Estabelecimento de Padrões de Identidade e Qualidade para Serviços e Produtos na Área de Alimentos. Diário Oficial da União 2 dez. 1993. Seção 1(229):18415.

7. Brasil. Ministério da Saúde. Secretaria de Vigilância Sanitária. Portaria no 326-SVS/MS de 30 de julho de 1997. Aprova o regulamento técnico; condições higiênicos- sanitárias e de boas práticas de fabricação para estabelecimentos produtores/industrializadores e de alimentos. Diário Oficial da União 1 ago. 1997; Seção 1(146):16560.

8. Brasil. Agência Nacional de Vigilância Sanitária. Resolução RDC nº 275, de 21 de Outubro de 2002. Dispõe sobre o Regulamento Técnico de Procedimentos Operacionais Padronizados aplicados aos Estabelecimentos Produtores/ Industrializadores de Alimentos e a Lista de Verificação das Boas Práticas de Fabricação em Estabelecimentos Produtores/Industrializadores de Alimentos. Diário Oficial da União 23 out. 2002; Seção 1:126.

9. Brasil. Agência Nacional de Vigilância Sanitária. Resolução RDC nº 216, de 15 de Setembro de 2004. Dispõe sobre Regulamento Técnico de Boas Práticas para Serviços de Alimentação. Diário Oficial da União 16 set. 2004; Seção 1:25.

10. Nascimento GA, Chiradia ACN. Levantamento das condições sanitárias dos quiosques das praias de Camburi e Curva da Jurema, da cidade de Vitória, Espírito Santo. Rev. Hig. Aliment. 2007; 21(152):18-24.

11. Almeida EB, Hostins RCL. O comportamento alimentar do turista e sua segurança no consumo de milho verde e churros à beira-mar. Revista Turismo Visão e Ação - Eletrônica. 2011; 13(3):347-361.

12. Fonseca MP, Manfridrini LA, São José JFB, Tomazini APB, Martini HSD, Ribeiro RCL, et al. Avaliação das condições físico-funcionais de restaurantes comerciais para Implementação das boas práticas. Alim. Nutr. 2010; 21(2):251-257. 
13. Silva Júnior EA. Manual de controle higiênico-sanitário em serviços de alimentação. $6^{a}$ ed. São Paulo: Varela; 2008.

14. São José JFB. Contaminação microbiológica em serviços de alimentação. Nutrire: Rev Soc Bras Alim Nutr. 2012; 37(1):78-92.

15. Colvara JG, Lima AS, Silva WP. Avaliação da contaminação de água subterrânea em poços artesianos no sul do Rio Grande do Sul. Braz. J. Food Technol. 2009; 2:11-14.

16. Gonçalves NA, Muniz KC, Soares ASN, Mollo VMH, Juzwiak CR. Aspectos sanitários dos quiosques da Praia do Itararé, em São Vicente, SP. Hig Aliment. 2008; 22(163):45-9.

17. Almeida EB. O Comportamento Alimentar do Turista e Sua Segurança no Consumo de Milho Verde e Churros à Beira Mar [dissertação]. Balneário Camburiú (SC): Universidade do Vale do Itajaí; 2008.

18. Souza CH, Sathler J, Jorge MN, Horst RFML. Avaliação das condições higiênico sanitárias em uma unidade de alimentação e nutrição hoteleira, na cidade de Timóteo, MG. Rev. Digital Nutrição 2009; 3(4):312-329.

19. Oliveira MN, Brasil ALD, Taddei JAAC. Avaliação das condições higiênico-sanitárias das cozinhas de creches públicas e filantrópicas. Ciênc. Saúde Col. 2008; 13(3):1051-1060.

Recebido: 10/6/2015

Revisado: 06/10/2015

Aprovado: 17/10/2015 